\title{
The Prevalence and Factors Associated with Musculoskeletal Pain Among Pilgrims During the
} Hajj

\author{
Mansour Abdullah Alshehri ${ }^{1,2}$ \\ Jamal Alzaidi ${ }^{3}$ \\ Sultan Alasmari ${ }^{3}$ \\ Ali Alfaqeh ${ }^{3}$ \\ Mohammad Arif $^{3}$ \\ Sultan Falh Alotaiby ${ }^{4}$ \\ Hosam Alzahrani $\mathbb{D}^{5}$
}

'Physiotherapy Department, Faculty of Applied Medical Sciences, Umm Al-Qura University, Mecca, Saudi Arabia; ${ }^{2}$ NHMRC Centre of Clinical Research Excellence in Spinal Pain, Injury and Health, School of Health and Rehabilitation Sciences, University of Queensland, Brisbane, QLD, Australia; ${ }^{3}$ Medical Rehabilitation Department, Makkah Health Affairs General Directorate, Mecca, Saudi Arabia; ${ }^{4}$ Physiotherapy Department, Hira General Hospital, Mecca, Saudi Arabia; ${ }^{5}$ Physiotherapy Department, College of Applied Medical Science, Taif University, Taif, Saudi Arabia

Correspondence: Mansour Abdullah Alshehri

Physiotherapy Department, Faculty of Applied Medical Sciences, Umm Al-Qura University, Al Awali, Mecca, 2438I, Saudi Arabia

Tel +966569693637

Email mamshehri@uqu.edu.sa
This article was published in the following Dove Press journal: Journal of Pain Research

Background: Musculoskeletal pain is a primary burden on individuals as well as social and health care systems. Annually, 2-3 million pilgrims perform the Hajj in Mecca, Saudi Arabia. The Hajj is highly physically demanding because pilgrims generally move by foot for long distances among a series of religious sites, an effort that may exceed their typical levels of physical activity. To understand the impact of musculoskeletal pain on the completion of the Hajj, it is first necessary to evaluate the extent of the problem. Accordingly, this study aimed to estimate the prevalence of musculoskeletal pain and associated factors among pilgrims during the Hajj.

Methods: A cross-sectional survey was conducted during the period of the Hajj. The participants were adult pilgrims $\geq 18$ years of age. Data regarding demographics, the prevalence of falls and the point prevalence of musculoskeletal pain by anatomical site were recorded. Participants were allowed to report more than one site of pain. Prevalence, crude and adjusted risk ratios were calculated.

Results: A total of 1715 pilgrims were included in the analysis. The prevalence of falls was $13.76 \%$. The prevalence of overall musculoskeletal pain (pain at any site) was $80.46 \%$. Musculoskeletal pain was most commonly reported in the ankle/foot (38.34\%), leg (29.89\%), lower back (28.47\%) and knee (21.84\%). In general, musculoskeletal pain at multiple sites was more common in females and in older and obese individuals. However, there were variations in the importance of sex, age and body mass index as associated factors across different pain sites.

Conclusion: Musculoskeletal pain is common among pilgrims. Unlike most populations examined in other studies, ankle/foot pain was the most common in pilgrims. These data provide guidance for potential preventative programs and the allocation of resources to optimize pilgrims' experiences and ability to complete the Hajj.

Keywords: musculoskeletal pain, falls, sex, age, BMI, Hajj

\section{Introduction}

Musculoskeletal pain is common and imposes a major burden on individuals as well as social and healthcare systems, ${ }^{1,2}$ affecting both sexes, all ages, and all sociocultural groups. ${ }^{1,3}$ Musculoskeletal pain is considered to be one of the most common causes of pain and physical disability, impacting hundreds of millions of people around the world. ${ }^{4,5}$ The prevalence of musculoskeletal pain is rising, and it has been described as an epidemic. ${ }^{1,6}$

"Hajj" is an Arabic word meaning "pilgrimage", 7 and it is the largest annual pilgrimage in the world, undertaken by Muslims at least once in their lifetime as a 
religious duty ${ }^{8-11}$ if they are financially and physically capable. ${ }^{12}$ Every year, around two to three million pilgrims converge simultaneously on the holy city of Mecca in Saudi Arabia (SA) for the rites of the Hajj, where they perform a series of rituals ${ }^{9,10,12,13}$ that were originally performed by the Prophet Mohammed. ${ }^{9}$ Based on the lunar Islamic year/calendar, the Hajj begins on the eighth day of Dhu al-Hijjah (the last month of the Islamic year) and ends on the twelfth day of the same month, ${ }^{10,12}$ although some pilgrims may spend further days to complete the Hajj. ${ }^{11}$ The date of the Hajj differs with respect to the Gregorian calendar, occurring 11 days earlier each year. $^{8}$

This mass gathering, which leads to extreme congestion in small areas, may contribute to one of the most important public health problems in the world, ${ }^{9,14}$ resulting in high environmental and healthcare demands. The Hajj also involves high physical demands because pilgrims move, generally by foot, among a series of religious sites over 5-7 days while following a specific route, with average distances of $5-15 \mathrm{~km} /$ day, ${ }^{8,11,15}$ potentially reaching a total of $63 \mathrm{~km}$ during the whole period of the Hajj. ${ }^{16}$ This likely exceeds the typical physical activity level of most individuals and is further complicated by overcrowding, extreme heat and fatigue. ${ }^{7,9,11,17}$ Many pilgrims also maximize prayers (Salat) during Hajj, ${ }^{18}$ which involve repetitive motions between a series of postures, including standing, bowing, prostration, and sitting. ${ }^{19}$ In addition, individuals' normal daily routines may be changed during the Hajj period as pilgrims move between places where the geography and climate are different, stay in tents and may neglect their self-health management while they are preoccupied with religious rituals. ${ }^{7,12}$

Many studies have been conducted to investigate health issues in pilgrims, with the main focus on infectious diseases ${ }^{9-}$ $12,14,20,21$ and other diseases, including cardiovascular diseases, neurological disorders, trauma, gastrointestinal problems, diabetes, heat exhaustion and dermatological diseases. ${ }^{7,10,14,15,22-}$ ${ }^{25}$ However, the prevalence of musculoskeletal pain among pilgrims during the Hajj and the potential associated factors have not been investigated. Thus, it is difficult to determine the impact of musculoskeletal pain on individuals who undertake the Hajj. Indeed, it is unclear whether the musculoskeletal pain among pilgrims is more prevalent in some physical sites than in others and whether the pain in these sites is associated with specific factors. To understand the potential impact of musculoskeletal pain on the completion of the Hajj, the development of preparatory advice and the preparation of support services, it is first necessary to evaluate the extent of the problem. Therefore, this study aimed to estimate the point prevalence of musculoskeletal pain by anatomical site among pilgrims during the Hajj and to study potential associations with individual characteristics.

\section{Materials and Methods Study Design}

A cross-sectional survey utilizing convenience sampling was conducted among pilgrims during the period of the Hajj. Ethical approval was obtained for the study from the Physiotherapy Research Committee of the Faculty of Applied Medical Sciences at Umm Al-Qura University in Mecca, SA. This study was registered at https://www. researchregistry.com in August 2018 (Research Registry Identifying Number: 4352), and it was conducted in accordance with the Declaration of Helsinki.

\section{Participants}

The participants were adult pilgrims aged 18 years or older of all nationalities, who had performed the Hajj in August 2018, which corresponded with Dhu al-Hijjah 1439 of the Hijri/ Islamic calendar. Any participants who had performed Umrah were excluded because Umrah involves some similar religious tasks and can be performed within a few hours, whereas the Hajj requires over 5-7 days to complete. Furthermore, all individuals who were working to serve and provide services to pilgrims (e.g., transportation, safety, social care, drifters care or healthcare) but did not perform the Hajj themselves were excluded. Informed consent was obtained, and all included participants agreed to participate.

\section{Data Collection}

The data were collected after completion of the second day of the Hajj from 21st to 31st August 2018 (10 to 20 Dhu al-Hijjah 1439 of the Hijri/Islamic calendar). The data were collected by qualified healthcare professionals, who approached individuals at different sites in Mecca using an online application or a paper form. Pilgrims were either questioned verbally by healthcare professionals or answered the questionnaire in person while healthcare professionals were nearby to explain any questions if they needed help. All healthcare professionals were trained to perform data collection in a standardized manner. All data were collected from all main sites of Hajj rituals, including Muzdalifah, Mina and the Holy Mosque. 
The data from the online survey were collected using a validated website (www.surveymonkey.com), and the data collected from the paper form were uploaded to the online application by the authors to obtain one single master file for both methods (online application and paper form). All information collected was anonymous, and only the authors had access to the data.

\section{Survey}

The survey data were sequentially collected (one by one) to avoid response bias in the sequence listed below. The survey was provided in two versions: an Arabic version and an English version (Supplementary material). The structure of the survey used in this study was as follows:

- Demographics: Participants were asked to answer questions about their nationality/country, sex, age and body mass index (BMI).

- Prevalence of falls: Participants were asked if they had lost their balance and fallen during the Hajj to estimate the prevalence of falls.

- Point prevalence of musculoskeletal pain: Participants were asked if they had experienced musculoskeletal pain or discomfort (by anatomical site) during the Hajj. All participants were allowed to report more than one site of pain.

\section{Sample Size Calculation}

According to a statistical report of the Saudi General Authority for Statistics in 2017, the total number of pilgrims who visited the holy city of Mecca in SA to perform the Hajj in 2017 was $2,352,122$. This estimated number includes Saudi $(n=209,415)$ and non-Saudi $(\mathrm{n}=2,142,707)$ pilgrims. ${ }^{26}$ Based on this information, it was assumed that around 2-3 million pilgrims would come to SA to perform the Hajj in 2018. Thus, the sample size was calculated by setting the statistical power at a $99 \%$ confidence interval, with a population size of 3,000,000 and a margin of error of $5 \%$, indicating that the required sample size for this study was 666 participants. After the completion of the Hajj 2018, the Saudi General Authority for Statistics revealed that the total number of pilgrims who performed the Hajj in 2018 was $2,371,675 .^{13}$ This estimation was within our assumed range of the total number of pilgrims to perform the Hajj in 2018 (2-3 million).

\section{Statistical Analysis}

Incomplete responses were discarded when there were no data available about the falls and musculoskeletal pain together. The findings were considered statistically significant when $\mathrm{P}<0.05$. The data were analyzed using StataIC version 16 (College Station, TX: StataCorp LLC).

Descriptive statistics (frequencies and percentages) were used to analyze participants' responses. The investigation of sex- and age-based differences has been recommended, which would provide further information of epidemiological data and contribute to a better understanding of the prevalence of musculoskeletal pain. ${ }^{27-29}$ Therefore, the prevalence and their $95 \%$ confidence intervals (CIs) were calculated, and Pearson's chisquared two-tailed tests were used to identify sex- and agebased differences in the following measures:

- Falls: The prevalence of falls was calculated for each age and sex group.

- Musculoskeletal pain: The prevalence of overall musculoskeletal pain (pain at any site), the prevalence of total lower limb pain (pain at hip/pelvis, thigh, knee, leg and ankle/foot) and the prevalence of musculoskeletal pain for each anatomical site (shoulder, upper arm, elbow, forearm, wrist/hand, head, cervical, thoracic, lumbar, hip/pelvis, thigh, knee, leg and ankle/foot) were calculated for each age and sex group. To adequately estimate the prevalence of musculoskeletal pain, only data from pilgrims who did not experience falls were calculated. This is because falls are acute events that may result in musculoskeletal pain, and thus they may be considered a causal pathway, whereas the majority of musculoskeletal pain in the pilgrims was probably due to repetitive motion or overuse.

The risk ratio (RR) for musculoskeletal pain was calculated to measure the association between an exposure and an outcome and to identify whether a specific exposure is a risk factor for a specific outcome. ${ }^{30}$ The result of the RR can be interpreted as follows: ${ }^{31}$ exposure does not affect the risk of the outcome $(R R=1)$, exposure is associated with a higher risk of the outcome $(R R>1)$ and exposure is associated with a lower risk of the outcome $(\mathrm{RR}<1)$. Binomial generalized linear models with a $\log$ link function were used to obtain RRs. ${ }^{30}$ The analyses were limited to most common/important sites of musculoskeletal pain. Two models were performed:

- Model 1: This model was a univariate regression analysis to estimate crude (unadjusted) RRs and their $95 \%$ CIs. 
- Model 2: This model was a multiple regression analysis to estimate RRs and their 95\% CIs with an adjustment for sex, age and BMI.

\section{Results}

\section{Characteristics of the Respondents}

A total of 2110 responses were received in the study, of which $32(1.52 \%)$ were from pilgrims who refused to participate, and 1715 (81.28\%) were from pilgrims who agreed to participate and provided complete information for all the survey sections. Data from 59 nationalities were recorded, the majority from Arabic nationalities. Characteristics of the included respondents for falls and musculoskeletal pain analyses are shown in Table 1.

\section{Prevalence of Falls}

The prevalence of falls was $13.76 \%$, and the prevalence was higher in females $(15.97 \%)$ than in males $(11.85 \%)$. The prevalence of falls was higher in older pilgrims (50-59 and $\geq 60$ age groups) than in younger pilgrims, with the largest difference between the males and the females observed in pilgrims who were older than 60 years of age (Table 2).

\section{Musculoskeletal Pain}

A total of 1479 responses were included in the analysis of the prevalence of musculoskeletal pain, while 236 responses received from participants who experienced falls were excluded from this analysis.

\section{Prevalence of Musculoskeletal Pain}

The prevalence of overall musculoskeletal pain was $80.46 \%$, with a prevalence of musculoskeletal pain for the total lower limb, total head/spine and total upper limb of $65.38 \%, 45.84 \%$ and $20.89 \%$, respectively. The most prevalent musculoskeletal pain by anatomical site among pilgrims was ankle/foot pain (38.34\%), followed by leg pain $(29.89 \%)$, low back pain $(28.47 \%)$ and knee pain $(21.84 \%)$, as shown in Figure 1. There were sex- and

Table I Characteristics of the Respondents

\begin{tabular}{|c|c|c|c|c|}
\hline \multirow[t]{2}{*}{ Variables } & & \multicolumn{3}{|l|}{$\mathbf{N}(\%)$} \\
\hline & & Male & Female & Total \\
\hline \multicolumn{5}{|c|}{ Respondents Included for Falls Analysis } \\
\hline Sex & & $920(53.64)$ & $795(46.36)$ & $1715(100)$ \\
\hline Age (years) & $\begin{array}{l}18-29 \\
30-39 \\
40-49 \\
50-59 \\
\geq 60\end{array}$ & $\begin{array}{l}307(52.03) \\
250(58.00) \\
142(49.65) \\
133(53.20) \\
88(55.70)\end{array}$ & $\begin{array}{l}283(47.97) \\
181(42.00) \\
144(50.35) \\
117(46.80) \\
70(44.30)\end{array}$ & $\begin{array}{l}590(34.40) \\
431(25.13) \\
286(16.68) \\
250(14.58) \\
158(9.21)\end{array}$ \\
\hline BMI $\left(\mathrm{kg} / \mathrm{cm}^{2}\right)$ & $\begin{array}{l}\text { Underweight }(<18.5) \\
\text { Normal weight }(18.5-24.9) \\
\text { Overweight }(25-29.9) \\
\text { Obese }(\geq 30)\end{array}$ & $\begin{array}{l}45(62.50) \\
379(50.60) \\
210(51.98) \\
286(58.37)\end{array}$ & $\begin{array}{l}27(37.50) \\
370(49.40) \\
194(48.02) \\
204(41.63)\end{array}$ & $\begin{array}{l}72(4.20) \\
749(43.67) \\
404(23.56) \\
490(28.57)\end{array}$ \\
\hline \multicolumn{5}{|c|}{ Respondents Included for Musculoskeletal Pain Analysis ${ }^{\mathbf{a}}$} \\
\hline Sex & & $811(54.83)$ & $668(45.17)$ & $1479(100)$ \\
\hline Age (years) & $\begin{array}{l}18-29 \\
30-39 \\
40-49 \\
50-59 \\
\geq 60\end{array}$ & $\begin{array}{l}283(53.60) \\
228(59.22) \\
123(50.20) \\
103(53.37) \\
74(57.81)\end{array}$ & $\begin{array}{l}245(46.40) \\
157(40.78) \\
122(49.80) \\
90(46.63) \\
54(42.19)\end{array}$ & $\begin{array}{l}528(35.70) \\
385(26.03) \\
245(16.57) \\
193(13.05) \\
128(8.65)\end{array}$ \\
\hline $\mathrm{BMI}\left(\mathrm{kg} / \mathrm{cm}^{2}\right)$ & $\begin{array}{l}\text { Underweight }(<18.5) \\
\text { Normal weight }(18.5-24.9) \\
\text { Overweight }(25-29.9) \\
\text { Obese }(\geq 30)\end{array}$ & $\begin{array}{l}39(61.90) \\
329(52.14) \\
188(53.11) \\
255(59.16)\end{array}$ & $\begin{array}{l}24(38.10) \\
302(47.86) \\
166(46.89) \\
176(40.84)\end{array}$ & $\begin{array}{l}63(4.26) \\
631(42.66) \\
354(23.94) \\
431(29.14)\end{array}$ \\
\hline
\end{tabular}

Note: ${ }^{a}$ Respondents who experienced falls $(n=263)$ during the Hajj were excluded from the musculoskeletal pain analysis.

Abbreviations: N, number; \%, percentage; BMl, body mass index; kg, kilogram; cm, centimeter. 
Table 2 Prevalence of Falls by Sex and Age

\begin{tabular}{|l|l|l|l|l|l|}
\hline \multicolumn{2}{|l|}{ Variables } & Male & Female & P-value & Male and Female \\
\hline Sex & & $11.85(9.92-14.10)$ & $15.97(13.59-18.68)$ & $\mathbf{0 . 0 1 3}$ & $13.76(12.21-15.47)$ \\
\hline Age Group & $18-29$ & $7.82(5.31-11.37)$ & $13.43(9.94-17.89)$ & $\mathbf{0 . 0 2 6}$ & $10.51(8.28-13.24)$ \\
& $30-39$ & $8.80(5.88-12.96)$ & $13.26(9.07-18.97)$ & 0.139 & $10.67(8.10-13.94)$ \\
& $40-49$ & $13.38(8.74-19.95)$ & $15.28(10.31-22.05)$ & 0.647 & $14.34(10.75-18.87)$ \\
& $50-59$ & $22.56(16.28-30.37)$ & $23.08(16.37-31.49)$ & 0.922 & $22.80(18.03-28.39)$ \\
& $\geq 60$ & $15.91(9.72-24.95)$ & $22.86(14.59-33.95)$ & 0.269 & $18.99(13.64-25.81)$ \\
& P-value & $\mathbf{0 . 0 0 0}$ & 0.054 & & $\mathbf{0 . 0 0 0}$ \\
\hline
\end{tabular}

Notes: The results of prevalence of falls with $95 \% \mathrm{Cls}$ are presented as percentages (\%). Based on Pearson's chi-squared tests, the $P$-values of statistically significant differences $(P<0.05)$ between sex and age groups are shown in bold.

age-based differences in multiple sites of pain (Table 3). The largest difference between males and females was observed for head and leg pain in younger pilgrims and for ankle/foot and knee pain in older pilgrims. The largest difference between younger and older pilgrims was observed for knee pain in both males and females.

\section{Factors Associated with Musculoskeletal Pain}

The ARRs results revealed (Table 4) that overall musculoskeletal pain was more common in females, while total lower limb musculoskeletal pain was more common in females and in older ( $\geq 60$ years) and obese individuals $\left(\geq 30 \mathrm{~kg} / \mathrm{cm}^{2}\right)$. Ankle/foot pain was less common in middle-aged (40-59 years) and older individuals ( $\geq 60$ years). Musculoskeletal pain at other common sites (lower back, knee and leg) was more common in females and in older and obese individuals (Table 5). There was a significant association between ankle/foot pain and pain in the lower back, knee and leg (Table 6).

\section{Discussion}

This study found that most pilgrims were at high risk of experiencing musculoskeletal pain during the Hajj, with the most prevalent forms being ankle/foot pain, leg pain, low back pain and knee pain. The study findings also confirmed significant associations between the prevalence of musculoskeletal pain and factors related to sex, age and BMI.

\section{Prevalence of Musculoskeletal Pain}

Most pilgrims (80.46\%) had at least one musculoskeletal complaint during the Hajj. This high prevalence rate is consistent with the findings of previous studies where the prevalence of musculoskeletal pain was $70 \%$ or higher for different specific populations including occupational drivers, agricultural farmers, marathon runners, nursing assistants, dentists and physiotherapists. ${ }^{32-38}$ However, several studies reported lower rates of musculoskeletal pain $(<25 \%)$, particularly among the general population in different countries, such as Sweden, Brazil and Japan, ${ }^{39-41}$ indicating that the prevalence of musculoskeletal pain among pilgrims is higher than in the general population.

Although a few studies are available in the literature that estimated or discussed the prevalence of musculoskeletal pain during religious mass gatherings such as the Hajj or Arbaeenia, these studies have not comprehensively investigated the prevalence of musculoskeletal pain. For example, one study was conducted in 2016 in Iraq during Arbaeenia in Karbala City and found that $28.2 \%$ of individuals had joint pain related to walking long distances. ${ }^{42}$ Another study was conducted during the Hajj in 2010 and reported that the prevalence of limb pain among pilgrims was $7 \%{ }^{43}$ The findings of both studies were inconsistent with the findings of the present study as we found a higher prevalence of musculoskeletal pain. This difference in prevalence rates could be explained by the fact that the two studies collected data only from healthcare facilities/ systems, whereas the majority of data in our study was from outside of healthcare facilities/systems since many pilgrims may not seek treatment or health services for mild musculoskeletal pain during the Hajj.

In the present study, the most common site of musculoskeletal pain was the ankle/foot $(38.34 \%)$, with a prevalence higher than that identified in most other studies. While some studies reported higher rates of ankle/foot pain among some specific populations, such as nurses $(43.8 \%)^{44}$ and housekeeping staff $(58.3-60.4 \%),{ }^{45}$ most studies reported lower rates of ankle/foot pain, with a prevalence lower than $20 \%$ in the general population or in specific populations such as nursing assistants, 


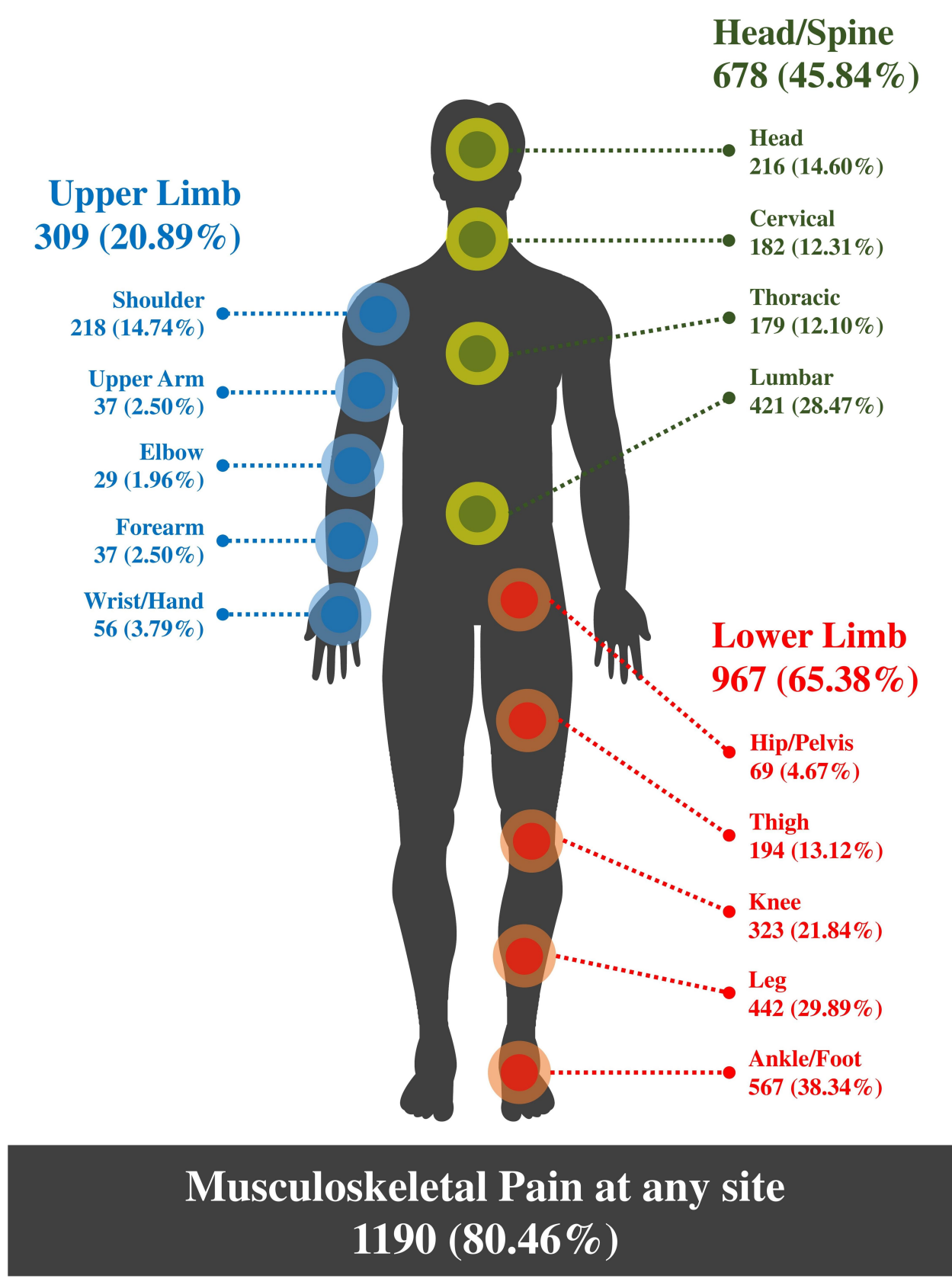

Figure I The prevalence of musculoskeletal pain by site. This figure shows the point prevalence of musculoskeletal pain among pilgrims. The results are presented as frequencies and percentages for each site.

occupational drivers, construction workers, agricultural farmers and marathon runners. ${ }^{32,33,35,39,46-50}$ There are possible explanations why our study showed a higher prevalence of ankle/foot pain among pilgrims. One is that the Hajj is highly physically demanding. Pilgrims move long distances, generally by foot, which may exceed their typical physical activity levels. ${ }^{7,9,11,17}$ Several studies have documented an association between jobs or activities/ tasks with high physical demands and musculoskeletal pain in different populations. ${ }^{34,39,42}$ For example, individuals who walk for long distances ${ }^{42}$ or primarily work while standing and for longer periods of time $\mathrm{e}^{51,52}$ as well as those who are exposed to high physical workloads ${ }^{46}$ have an increased risk of musculoskeletal pain, particularly in the lower limbs. ${ }^{46,52}$ Another possible explanation could be related to the use of poorly fitting footwear/shoes among pilgrims, which may not be suitable to wear during the Hajj. Multiple studies have shown that poorly and incorrectly fitting shoes are significantly associated with ankle and foot pain, ${ }^{53,54}$ implying the 
Table 3 Point Prevalence of Musculoskeletal Pain by Anatomical Site, Sex and Age

\begin{tabular}{|c|c|c|c|c|c|c|c|}
\hline \multirow[t]{2}{*}{ Pain Site } & \multirow[t]{2}{*}{ Sex } & \multicolumn{5}{|l|}{ Age Group } & \multirow[t]{2}{*}{$P$-value } \\
\hline & & $18-29$ & $30-39$ & $40-49$ & $50-59$ & $\geq \mathbf{6 0}$ & \\
\hline \multirow[t]{2}{*}{ Shoulder } & Male & $12.37(9.03-16.71)$ & $13.16(9.37-18.16)$ & $7.32(3.90-13.32)$ & $16.50(10.57-24.85)$ & $14.86(8.5 \mid-24.69)$ & 0.290 \\
\hline & Female & $17.14(12.94-22.36)$ & $17.83(12.64-24.57)$ & $20.49(14.28-28.50)$ & 16.67 (10.37-25.69) & 11.11 (5.19-22.19) & 0.669 \\
\hline \multirow[t]{2}{*}{ Upper Arm } & Male & $1.41(0.55-3.58)$ & $3.95(2.09-7.33)$ & $4.88(2.25-10.23)$ & $1.94(0.53-6.81)$ & $2.70(0.74-9.33)$ & 0.261 \\
\hline & Female & $3.27(1.66-6.31)$ & $3.18(1.37-7.24)$ & $0.00(0.00-3.05)$ & $0.00(0.00-4.09)$ & $1.85(0.33-9.77)$ & 0.131 \\
\hline \multirow[t]{2}{*}{ Elbow } & Male & $1.41(0.55-3.58)$ & $2.19(0.94-5.03)$ & $1.63(0.45-5.74)$ & $0.97(0.17-5.30)$ & 4.05 (1.39-11.25) & 0.575 \\
\hline & Female & 0.41 (7e-04-2.28) & $3.18(1.37-7.24)$ & $2.46(0.84-6.98)$ & $4.44(1.74-10.88)$ & $1.85(0.33-9.77)$ & 0.146 \\
\hline \multirow[t]{2}{*}{ Forearm } & Male & $1.77(0.76-4.07)$ & $2.19(0.94-5.03)$ & $1.63(0.45-5.74)$ & $4.85(2.09-10.86)$ & 4.05 (1.39-11.25) & 0.376 \\
\hline & Female & $3.27(1.66-6.31)$ & $1.27(0.35-4.53)$ & $0.82(0.14-4.50)$ & $5.56(2.40-12.35)$ & $1.85(0.33-9.77)$ & 0.172 \\
\hline \multirow[t]{2}{*}{ Wrist/Hand } & Male & $3.53(1.93-6.38)$ & $1.75(0.68-4.42)$ & $1.63(0.45-5.74)$ & $5.83(2.70-12.13)$ & $8.11(3.77-16.58)$ & 0.045 \\
\hline & Female & $3.27(1.66-6.31)$ & $3.18(1.37-7.24)$ & $4.10(1.76-9.24)$ & $10.00(5.35-17.92)$ & $1.85(0.33-9.77)$ & 0.056 \\
\hline \multirow[t]{2}{*}{ Head } & Male & $12.72(9.33-17.11)$ & $10.09(6.82-14.68)$ & $12.20(7.53-19.15)$ & $15.53(9.79-23.75)$ & $16.22(9.53-26.24)$ & 0.555 \\
\hline & Female & $14.69(10.81-19.67)$ & $23.57(17.61-30.79)$ & 19.67 (13.59-27.60) & $15.56(9.50-24.43)$ & $5.56(1.91-15.11)$ & 0.022 \\
\hline \multirow[t]{2}{*}{ Neck } & Male & $6.36(4.06-9.83)$ & $12.28(8.63-17.18)$ & $11.38(6.90-18.20)$ & $17.48(11.35-25.94)$ & $17.57(10.56-27.77)$ & 0.007 \\
\hline & Female & $17.14(12.94-22.36)$ & $13.38(8.92-19.58)$ & $13.11(8.24-20.25)$ & $10.00(5.35-17.92)$ & $5.56(1.91-15.11)$ & 0.158 \\
\hline \multirow[t]{2}{*}{ Thoracic } & Male & $13.07(9.64-17.50)$ & $10.96(7.54-15.69)$ & $8.13(4.48-14.32)$ & $12.62(7.53-20.40)$ & $13.5 \mid(7.5 \mid-23.12)$ & 0.650 \\
\hline & Female & $13.88(10.10-18.77)$ & I2.74 (8.40-18.86) & $6.56(3.36-12.4 I)$ & 17.78 (11.25-26.94) & 11.11 (5.19-22.19) & 0.151 \\
\hline \multirow[t]{2}{*}{ Lumbar } & Male & $19.43(15.25-24.44)$ & $28.07(22.64-34.23)$ & $28.46(21.23-36.99)$ & $32.04(23.8 I-4 I .56)$ & $36.49(26.44-47.87)$ & 0.010 \\
\hline & Female & 31.43 (25.94-37.49) & $32.48(25.65-40.15)$ & $32.79(25.09-41.53)$ & $21.11(13.95-30.63)$ & $37.04(25.42-50.37)$ & 0.249 \\
\hline \multirow[t]{2}{*}{ Hip/Pelvis } & Male & $1.41(0.55-3.58)$ & $2.19(0.94-5.03)$ & $1.63(0.45-5.74)$ & $2.91(1.00-8.22)$ & $13.5 \mid(7.5 \mid-23.12)$ & 0.000 \\
\hline & Female & $6.12(3.75-9.85)$ & $2.55(1.00-6.37)$ & $6.56(3.36-12.4 I)$ & 14.44 (8.64-23.16) & $9.26(4.02-19.91)$ & 0.009 \\
\hline \multirow[t]{2}{*}{ Thigh } & Male & II.66 (8.42-| 5.92) & $13.16(9.37-18.16)$ & $8.94(5.07-15.31)$ & $10.68(6.07-18.12)$ & $17.57(10.56-27.77)$ & 0.445 \\
\hline & Female & 19.59 (I5.II-25.0I) & I3.38 (8.92-19.58) & $12.30(7.59-19.30)$ & $11.11(6.15-19.26)$ & $3.70(1.02-12.54)$ & 0.019 \\
\hline \multirow[t]{2}{*}{ Knee } & Male & 12.37 (9.03-16.7I) & 17.98 (13.54-23.48) & 19.51 (13.48-27.39) & $30.10(22.09-39.54)$ & 39.19 (28.86-50.58) & 0.000 \\
\hline & Female & $17.96(13.66-23.25)$ & I4.0I (9.44-20.31) & $28.69(21.4 I-37.27)$ & $46.67(36.7 I-56.90)$ & $37.04(25.42-50.37)$ & 0.000 \\
\hline \multirow[t]{2}{*}{ Leg } & Male & $24.03(19.42-29.33)$ & $25.44(20.22-31.47)$ & $26.02(19.07-34.4 I)$ & $24.27(17.02-33.38)$ & 43.24 (32.57-54.59) & 0.018 \\
\hline & Female & $36.33(30.56-42.52)$ & $28.03(21.59-35.51)$ & $30.33(22.87-38.98)$ & 38.89 (29.47-49.22) & $40.74(28.68-54.03)$ & 0.209 \\
\hline \multirow[t]{2}{*}{ Ankle/Foot } & Male & $43.46(37.8 I-49.29)$ & $37.72(31.68-44.17)$ & $35.77(27.85-44.56)$ & $24.27(17.02-33.38)$ & $35.14(25.24-46.50)$ & 0.015 \\
\hline & Female & $42.86(36.82-49.12)$ & $40.76(33.39-48.58)$ & $34.43(26.59-43.22)$ & $4 I .1 I(3 I .5 I-5 I .44)$ & $27.78(17.62-40.89)$ & 0.216 \\
\hline \multirow[t]{2}{*}{ Lower Extremity $^{\mathrm{a}}$} & Male & $57.60(51.78-63.22)$ & $60.09(53.6 I-66.23)$ & $60.98(52.15-69.14)$ & $59.22(49.57-68.22)$ & $77.03(66.25-85.13)$ & 0.049 \\
\hline & Female & 71.84 (65.90-77.10) & $66.24(58.54-73.17)$ & $68.85(60.17-76.39)$ & 78.89 (69.37-86.05) & $72.22(59.11-82.38)$ & 0.304 \\
\hline \multirow[t]{2}{*}{ All ${ }^{b}$} & Male & $69.96(64.39-75.01)$ & $77.19(71.32-82.16)$ & $80.49(72.61-86.52)$ & 78.64 (69.77-85.45) & 83.78 (73.76-90.47) & 0.040 \\
\hline & Female & 85.71 (80.78-89.55) & $82.80(76.13-87.90)$ & 86.89 (79.75-91.76) & $90.00(82.08-94.65)$ & 87.04 (75.58-93.58) & 0.616 \\
\hline
\end{tabular}

Notes: ${ }^{2}$ Musculoskeletal pain at the hip/pelvis, thigh, knee, leg and ankle/foot sites. ${ }^{b}$ Musculoskeletal pain at any site. The results of point prevalence of musculoskeletal pain with $95 \% \mathrm{Cls}$ are presented as percentages (\%). Based on Pearson's chi-squared tests, the values of statistically significant differences $(P<0.05)$ between sexes (prevalence values) and age groups ( $P$-values) are shown in bold.

importance of using properly fitting footwear. Therefore, pilgrims are at a higher risk of developing musculoskeletal pain, especially pain in the ankle/foot.

\section{Factors Associated with Musculoskeletal Pain}

The present study showed that the prevalence of overall musculoskeletal pain was greater in females and older individuals, in line with previous studies showing that sex and age are a risk factor for musculoskeletal pain. These studies reported a higher prevalence of musculoskeletal pain in females than in males ${ }^{39-41,55-57}$ and in older individuals than in younger individuals. ${ }^{39,40,57}$ BMI was not associated with overall musculoskeletal pain in our study. In contrast, numerous studies reported that musculoskeletal pain was more common in individuals with a BMI exceeding that of normal-weight individuals. ${ }^{40,51}$ However, we found that a BMI of $30 \mathrm{~kg} / \mathrm{cm}^{2}$ or greater 
Table 4 Risk Ratios for Overall (Pain at Any Site) and Total Lower Limb (Pain in the Hip/Pelvis, Thigh, Knee, Leg and Ankle/Foot) Musculoskeletal Pain in the Hajj Population by Sex, Age and BMI

\begin{tabular}{|c|c|c|c|c|c|}
\hline \multicolumn{2}{|l|}{ Variables } & Model I (CRR) ${ }^{\mathbf{a}}$ & $P$-value & Model 2 (ARR) & $P$-value \\
\hline \multicolumn{6}{|c|}{ Overall Musculoskeletal Pain } \\
\hline Sex & $\begin{array}{l}\text { Male } \\
\text { Female }\end{array}$ & I.I3 (1.08-I.19) & 0.000 & $1.13(1.07-1.18)$ & 0.000 \\
\hline Age (years) & $\begin{array}{l}18-29 \\
30-39 \\
40-49 \\
50-59 \\
\geq 60\end{array}$ & $\begin{array}{l}\text { I } \\
1.03(0.96-1.10) \\
1.08(1.01-1.16) \\
1.09(1.01-1.17) \\
1.10(1.01-1.20)\end{array}$ & $\begin{array}{l}- \\
0.421 \\
0.031 \\
0.036 \\
0.027\end{array}$ & $\begin{array}{l}\text { I } \\
1.02(0.95-1.09) \\
1.06(0.99-1.14) \\
1.07(0.99-1.15) \\
1.07(0.98-1.16)\end{array}$ & $\begin{array}{l}- \\
0.632 \\
0.121 \\
0.092 \\
0.140\end{array}$ \\
\hline BMI $\left(\mathrm{kg} / \mathrm{cm}^{2}\right)$ & $\begin{array}{l}<18.5 \\
18.5-24.9 \\
25-29.9 \\
\geq 30\end{array}$ & $\begin{array}{l}1.00(0.88-1.15) \\
\text { I } \\
1.03(0.96-1.10) \\
1.04(0.98-1.10)\end{array}$ & $\begin{array}{l}0.958 \\
- \\
0.358 \\
0.251\end{array}$ & $\begin{array}{l}1.03(0.91-1.17) \\
\text { I } \\
1.02(0.96-1.09) \\
1.03(0.97-1.09)\end{array}$ & $\begin{array}{l}0.652 \\
- \\
0.469 \\
0.338\end{array}$ \\
\hline \multicolumn{6}{|c|}{ Total Lower Limb Musculoskeletal Pain } \\
\hline Sex & $\begin{array}{l}\text { Male } \\
\text { Female }\end{array}$ & $1.17(1.08-1.26)$ & $\begin{array}{l}- \\
0.000\end{array}$ & $1.16(1.08-1.25)$ & $\overline{0.000}$ \\
\hline Age (years) ${ }^{c}$ & $\begin{array}{l}18-29 \\
30-39 \\
40-49 \\
50-59 \\
\geq 60\end{array}$ & $\begin{array}{l}\mathrm{I} \\
0.97(0.88-1.08) \\
1.01(0.90-1.13) \\
1.07(0.95-1.20) \\
1.17(1.04-1.32)\end{array}$ & $\begin{array}{l}- \\
0.620 \\
0.851 \\
0.282 \\
\mathbf{0 . 0 1 0}\end{array}$ & $\begin{array}{l}\mathrm{I} \\
0.98(0.88-1.08) \\
0.99(0.89-1.12) \\
\mathrm{I} .07(0.96-1.20) \\
\mathrm{I} .14(\mathrm{I} .02-1.28)\end{array}$ & $\begin{array}{l}- \\
0.618 \\
0.983 \\
0.228 \\
\mathbf{0 . 0 2 4}\end{array}$ \\
\hline BMI $\left(\mathrm{kg} / \mathrm{cm}^{2}\right)^{\mathrm{d}}$ & $\begin{array}{l}<18.5 \\
18.5-24.9 \\
25-29.9 \\
\geq 30\end{array}$ & $\begin{array}{l}0.99(0.82-1.2 \mathrm{I}) \\
\mathrm{I} \\
\mathrm{I} .0 \mathrm{I}(0.92-\mathrm{I} . \mathrm{II}) \\
\mathrm{I} .07(0.98-1.16)\end{array}$ & $\begin{array}{l}0.933 \\
- \\
0.834 \\
0.154\end{array}$ & $\begin{array}{l}1.03(0.85-1.26) \\
I \\
1.03(0.93-1.13) \\
1.09(1.01-1.19)\end{array}$ & $\begin{array}{l}0.731 \\
- \\
0.610 \\
\mathbf{0 . 0 3 9}\end{array}$ \\
\hline
\end{tabular}

Notes: ${ }^{a}$ Unadjusted risk ratio. ${ }^{b}$ Risk ratio adjusted for sex, age and BMI. ${ }^{\mathrm{C}}$ Risk ratio adjusted for only sex and age as the convergence was not achieved when a third factor

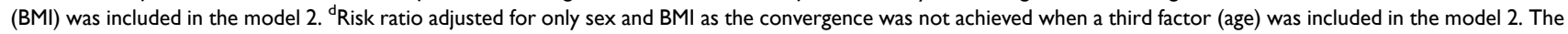
results are presented as risk ratios with $95 \% \mathrm{Cls}$. Based on log-binomial models, the $P$-values of statistically significant associations $(P<0.05)$ are shown in bold.

Abbreviations: $\mathrm{CRR}$, crude risk ratio; ARR, adjusted risk ratio; $\mathrm{Cl}$, confidence interval; $\mathrm{BMI}$, body mass index; kg, kilogram; cm, centimeter.

was associated with a higher prevalence of total lower limb musculoskeletal pain.

In terms of the most prevalent site of musculoskeletal pain among the pilgrims in our study, sex and BMI were not associated with ankle/foot pain. In contrast, several studies found that females ${ }^{39,47,49-51,58}$ and obese individuals ${ }^{44,49,58}$ were at higher risk of ankle/foot pain. In our study, age was associated with ankle/foot pain in pilgrims, as older pilgrims reported less ankle/foot pain than younger pilgrims. This finding is inconsistent with several previous studies reporting that older pilgrims were at higher risk of ankle/foot pain than younger individuals. ${ }^{33,47,49,50,59}$ This difference could be explained by the fact that the majority of our participants were young or middle-aged adults ( $\leq 59$ years, $91.35 \%$ ). Additionally, older pilgrims may seek help to move between rituals sites during the Hajj, using wheelchairs or transportation services. However, we found that older pilgrims were at increased risk of musculoskeletal pain in other common sites, such as the leg, knee and lower back. In our study, we also found that pilgrims who reported pain in the leg, knee and lower back were more likely to report ankle/foot pain. This finding is similar to those of previous studies that found an association between ankle/foot pain and pain in other anatomical sites, including the leg, ${ }^{58} \mathrm{knee}^{49,50,58}$ and back. $^{49,50,58}$

\section{Study Strengths and Limitations}

To the best of our knowledge, this is the first study to comprehensively investigate the prevalence of musculoskeletal pain among pilgrims. One strength of this study is that a sample size calculation was performed, and the required sample size was achieved. The data were 
Table 5 Risk Ratios for the Most Common Sites of Musculoskeletal Pain in the Hajj Population by Sex, Age and BMI

\begin{tabular}{|c|c|c|c|c|c|c|c|c|c|}
\hline \multicolumn{2}{|l|}{ Variables } & Model I (CRR) ${ }^{a}$ & $P$-value & Model 2 (ARR) & $P$-value & Model I (CRR) ${ }^{a}$ & $P$-value & Model 2 (ARR) ${ }^{b}$ & $P$-value \\
\hline & & \multicolumn{4}{|l|}{ Ankle/Foot Pain } & \multicolumn{4}{|l|}{ Leg Pain } \\
\hline Sex & $\begin{array}{l}\text { Male } \\
\text { Female }\end{array}$ & $\begin{array}{l}\text { I } \\
1.05(0.92-1.20)\end{array}$ & $\begin{array}{l}- \\
0.457\end{array}$ & $\begin{array}{l}1 \\
1.05(0.92-1.20)\end{array}$ & $\begin{array}{l}- \\
0.444\end{array}$ & $\begin{array}{l}1 \\
1.28(1.10-1.50)\end{array}$ & 0.002 & $\begin{array}{l}\text { I } \\
1.28(1.09-1.49)\end{array}$ & $\begin{array}{l}- \\
0.002\end{array}$ \\
\hline Age (years) & $\begin{array}{l}18-29 \\
30-39 \\
40-49 \\
50-59 \\
\geq 60\end{array}$ & $\begin{array}{l}\text { I } \\
0.90(0.77-1.06) \\
0.81(0.67-0.99) \\
0.74(0.59-0.93) \\
0.74(0.57-0.97)\end{array}$ & $\begin{array}{l}- \\
0.204 \\
\mathbf{0 . 0 3 9} \\
\mathbf{0 . 0 1 1} \\
\mathbf{0 . 0 3 1}\end{array}$ & $\begin{array}{l}\text { I } \\
0.90(0.77-1.06) \\
0.81(0.66-0.99) \\
0.74(0.59-0.93) \\
0.74(0.56-0.97)\end{array}$ & $\begin{array}{l}- \\
0.202 \\
\mathbf{0 . 0 4 5} \\
\mathbf{0 . 0 1 1} \\
\mathbf{0 . 0 3 2}\end{array}$ & $\begin{array}{l}1 \\
0.89(0.72-1.10) \\
0.95(0.75-1.20) \\
1.05(0.82-1.34) \\
1.42(1.11-1.81)\end{array}$ & $\begin{array}{l}- \\
0.286 \\
0.656 \\
0.725 \\
\mathbf{0 . 0 0 5}\end{array}$ & $\begin{array}{l}\text { I } \\
0.88(0.71-1.10) \\
0.92(0.72-1.17) \\
1.03(0.80-1.33) \\
1.39(1.08-1.78)\end{array}$ & $\begin{array}{l}- \\
0.260 \\
0.494 \\
0.821 \\
0.010\end{array}$ \\
\hline \multirow[t]{2}{*}{ BMI $\left(\mathrm{kg} / \mathrm{cm}^{2}\right)$} & $\begin{array}{l}<18.5 \\
18.5-24.9 \\
25-29.9 \\
\geq 30\end{array}$ & $\begin{array}{l}0.99(0.72-1.37) \\
1 \\
0.85(0.71-1.01) \\
0.99(0.85-1.15)\end{array}$ & $\begin{array}{l}0.969 \\
- \\
0.065 \\
0.872\end{array}$ & $\begin{array}{l}0.97(0.70-1.33) \\
1 \\
0.91(0.76-1.08) \\
1.07(0.91-1.25)\end{array}$ & $\begin{array}{l}0.842 \\
- \\
0.278 \\
0.408\end{array}$ & $\begin{array}{l}0.86(0.55-1.33) \\
1 \\
1.03(0.84-1.25) \\
1.03(0.85-1.24)\end{array}$ & $\begin{array}{l}0.492 \\
- \\
0.774 \\
0.791\end{array}$ & $\begin{array}{l}0.85(0.55-1.32) \\
1 \\
1.01(0.83-1.24) \\
1.01(0.84-1.23)\end{array}$ & $\begin{array}{l}0.463 \\
- \\
0.914 \\
0.889\end{array}$ \\
\hline & & \multicolumn{4}{|l|}{ Low Back Pain } & \multicolumn{4}{|l|}{ Knee Pain } \\
\hline Sex & $\begin{array}{l}\text { Male } \\
\text { Female }\end{array}$ & $\begin{array}{l}\text { I } \\
1.17(0.99-1.38)\end{array}$ & $\begin{array}{l}- \\
0.051\end{array}$ & 1 I.18 (1.01-1.39) & 0.045 & $\begin{array}{l}\text { I } \\
1.24(1.02-1.50)\end{array}$ & - & $\begin{array}{l}1 \\
1.23(1.02-1.48)\end{array}$ & 0.029 \\
\hline Age (years) & $\begin{array}{l}18-29 \\
30-39 \\
40-49 \\
50-59 \\
\geq 60\end{array}$ & $\begin{array}{l}\text { I } \\
1.19(0.97-1.48) \\
1.22(0.96-1.56) \\
1.07(0.82-1.41) \\
1.47(1.12-1.93)\end{array}$ & $\begin{array}{l}- \\
0.101 \\
0.097 \\
0.594 \\
\mathbf{0 . 0 0 5}\end{array}$ & $\begin{array}{l}\text { I } \\
1.13(0.91-1.40) \\
1.13(0.89-1.45) \\
0.98(0.73-1.29) \\
1.36(1.03-1.80)\end{array}$ & $\begin{array}{l}- \\
0.257 \\
0.323 \\
0.863 \\
\mathbf{0 . 0 2 8}\end{array}$ & $\begin{array}{l}\text { I } \\
1.09(0.81-1.48) \\
1.61(1.19-2.18) \\
2.53(1.93-3.32) \\
2.56(1.90-3.45)\end{array}$ & $\begin{array}{l}- \\
0.564 \\
\mathbf{0 . 0 0 2} \\
\mathbf{0 . 0 0 0} \\
\mathbf{0 . 0 0 0}\end{array}$ & $\begin{array}{l}1 \\
1.06(0.78-1.44) \\
1.50(1.10-2.05) \\
2.33(1.75-3.10) \\
2.37(1.74-3.22)\end{array}$ & $\begin{array}{l}- \\
0.724 \\
0.010 \\
0.000 \\
0.000\end{array}$ \\
\hline BMI $\left(\mathrm{kg} / \mathrm{cm}^{2}\right)$ & $\begin{array}{l}<18.5 \\
18.5-24.9 \\
25-29.9 \\
\geq 30\end{array}$ & $\begin{array}{l}0.60(0.33-1.07) \\
1 \\
1.11(0.90-1.37) \\
1.23(1.02-1.48)\end{array}$ & $\begin{array}{l}0.086 \\
- \\
0.324 \\
\mathbf{0 . 0 3 3}\end{array}$ & $\begin{array}{l}0.62(0.35-1.12) \\
1 \\
1.08(0.87-1.33) \\
1.20(0.99-1.46)\end{array}$ & $\begin{array}{l}0.114 \\
- \\
0.494 \\
0.062\end{array}$ & $\begin{array}{l}0.99(0.57-1.74) \\
1 \\
1.28(0.99-1.66) \\
1.60(1.27-2.00)\end{array}$ & $\begin{array}{l}0.979 \\
- \\
0.055 \\
\mathbf{0 . 0 0 0}\end{array}$ & $\begin{array}{l}1.06(0.61-1.84) \\
1 \\
1.10(0.85-1.42) \\
1.30(1.03-1.64)\end{array}$ & $\begin{array}{l}0.836 \\
- \\
0.458 \\
\mathbf{0 . 0 2 5}\end{array}$ \\
\hline
\end{tabular}

Notes: ${ }^{a}$ Unadjusted risk ratio. ${ }^{b}$ Risk ratio adjusted for sex, age and BMI. The results are presented as risk ratios with $95 \%$ Cls. Based on log-binomial models, the $P$-values of statistically significant associations $(P<0.05)$ are shown in bold.

Abbreviations: BMI, body mass index; CRR, crude risk ratio; ARR, adjusted risk ratio; $\mathrm{Cl}$, confidence interval; kg, kilogram; cm, centimeter.

collected by qualified healthcare professionals, who were trained to perform the data collection in a standardized manner. Another strength is the investigation of the association between musculoskeletal pain and potential associated factors (sex, age and BMI). Nonetheless, there were some limitations to the current study. There was a potential sampling bias due to the use of convenience sampling, so the sample may not be representative of the entire pilgrim population that visited Mecca to perform the Hajj. However, an attempt was made to reduce the sampling bias by distributing the survey at different major sites of Hajj rituals. This study also used a crosssectional design, which is limited to demonstrating a causal association.

Table 6 Association Between Ankle/Foot Pain and Pain in the Leg, Knee and Lower Back

\begin{tabular}{|c|c|c|c|c|c|}
\hline \multicolumn{2}{|l|}{ Variables } & \multirow{2}{*}{$\begin{array}{l}\text { Model I (CRR) } \\
1 \\
1.44(1.27-1.64)\end{array}$} & \multirow{2}{*}{$\begin{array}{l}P \text {-value } \\
- \\
0.000\end{array}$} & \multirow{2}{*}{$\begin{array}{l}\text { Model } 2 \text { (ARR) }^{\mathbf{b}} \\
\text { I } \\
1.47(1.29-1.67)\end{array}$} & \multirow{2}{*}{$\begin{array}{l}P \text {-value } \\
- \\
0.000\end{array}$} \\
\hline Leg & $\begin{array}{l}\text { No pain } \\
\text { Pain }\end{array}$ & & & & \\
\hline Knee & $\begin{array}{l}\text { No pain } \\
\text { Pain }\end{array}$ & $\begin{array}{l}\text { I } \\
1.35(1.17-1.54)\end{array}$ & $\begin{array}{l}- \\
0.000\end{array}$ & I. $13(1.25-1.65)$ & $\begin{array}{l}- \\
0.000\end{array}$ \\
\hline Lower back & $\begin{array}{l}\text { No pain } \\
\text { Pain }\end{array}$ & $\begin{array}{l}\text { I } \\
\text { I.21 (1.06-1.39) }\end{array}$ & $\begin{array}{l}- \\
0.004\end{array}$ & $\begin{array}{l}\text { I } \\
1.24(1.08-1.42)\end{array}$ & $\begin{array}{l}- \\
0.002\end{array}$ \\
\hline
\end{tabular}

Notes: ${ }^{a}$ Unadjusted risk ratio. ${ }^{b}$ Risk ratio adjusted for sex, age and BMI. Based on log-binomial models, the $P$-values of statistically significant associations $(P<0.05)$ are shown in bold.

Abbreviations: CRR, crude risk ratio; ARR, adjusted risk ratio; $\mathrm{Cl}$, confidence interval; $\mathrm{BMI}$, body mass index; $\mathrm{kg}$, kilogram; cm, centimeter. 


\section{Conclusion}

The findings of this study indicate that musculoskeletal pain is common among pilgrims, and the reported prevalence of musculoskeletal pain is greater among pilgrims than that reported for the general population. This signals a significant public health issue that must be addressed by the Saudi Ministry of Health. Unlike most populations, the ankle/foot was the most common site of musculoskeletal pain among pilgrims. The study also demonstrates that sex, age and BMI were associated with the prevalence of musculoskeletal pain, and the importance of these factors varied across different pain sites.

\section{Acknowledgments}

The authors would like to thank all of the healthcare professionals for their help during the data collection, including distribution of the study survey and collection of the data directly from pilgrims. These healthcare professionals were (in alphabetical order): Ammar Mansour Algethami, Bushra Tysyer Al-shalabi, Dania Ayman Bresaly, Elaf Abdulrahman Badr, Futon Wajdy Albarakati, Hessa Metleq Alkhuzai, Hind Nasser Al-kabbi, Khadigah Ahmad Mouaz, Mahmoud Jamil Merdad, Meshari Ali Alhazmi, Mudah Saud Hunaidi, Muhannad Yasser Daba, Nazeha Basim Shafi, Nouf Abdulelah Allehaibi, Raed Saleh Almalki, Rashed Saleh Alharthi, Rawan Ibrahim Motwakel, Rawan Ismail Nouruldeen, Seham Hamdi Alsulami, Shimaa Abd ELRahman Abbas, Waad Mohammed Alsulami, Yahya Ahmad Alamry and Zainelabdin Abubakr Elaidarous. The authors would also like to thank all of the pilgrims who were kind and agreed to participate in the study. HA acknowledges Taif University Researchers Supporting Project number (TURSP-2020/238), Taif University, Taif, Saudi Arabia.

\section{Funding}

The authors did not receive any funding to conduct this study.

\section{Disclosure}

The author reports no conflicts of interest in this work.

\section{References}

1. WHO. Scientific Group on the Burden of Musculoskeletal Conditions at the Start of the New Millennium, and World Health Organization. The Burden of Musculoskeletal Conditions at the Start of the New Millennium: Report of a WHO Scientific Group. World Health Organization; 2003.
2. Arendt-Nielsen L, Fernández-de-las-Peñas C, Graven-Nielsen T. Basic aspects of musculoskeletal pain: from acute to chronic pain. $J$ Man Manip Ther. 2011;19(4):186-193. doi:10.1179/10669811 1X13129729551903

3. Briggs AM, Woolf AD, Dreinhöfer K, et al. Reducing the global burden of musculoskeletal conditions. Bull World Health Organ. 2018;96(5):366-368. doi:10.2471/BLT.17.204891

4. Vos T, Allen C, Arora M, et al. Global, regional, and national incidence, prevalence, and years lived with disability for 310 diseases and injuries, 1990-2015: a systematic analysis for the global burden of disease study 2015. Lancet. 2016;388(10053):1545-1602.

5. James SL, Abate D, Abate KH, et al. Global, regional, and national incidence, prevalence, and years lived with disability for 354 diseases and injuries for 195 countries and territories, 1990-2017: a systematic analysis for the global burden of disease study 2017. Lancet. 2018;392(10159):1789-1858.

6. Main CJ, Williams AC. Musculoskeletal pain. BMJ. 2002;325 (7363):534-537. doi:10.1136/bmj.325.7363.534

7. Alsafadi H, Goodwin W, Syed A. Diabetes care during hajj. Clin Med. 2011;11(3):218-221. doi:10.7861/clinmedicine.11-3-218

8. Parker S, Gaines J. Saudi Arabia: hajj/umrah pilgrimage. Centers for disease control and prevention. Available from: https://wwwnc.cdc. gov/travel/yellowbook/2020/popular-itineraries/saudi-arabia-hajjum rah-pilgrimage. Accessed January 1, 2020.

9. Ahmed QA, Arabi YM, Memish ZA. Health risks at the hajj. Lancet. 2006;367(9515):1008-1015. doi:10.1016/S0140-6736(06)68429-8

10. Shafi S, Dar O, Khan M, et al. The annual hajj pilgrimage-minimizing the risk of ill health in pilgrims from Europe and opportunity for driving the best prevention and health promotion guidelines. Int $J$ Infect Dis. 2016;47:79-82. doi:10.1016/j.ijid.2016.06.013

11. Mandourah Y, Al-Radi A, Ocheltree AH, Ocheltree SR, Fowler RA. Clinical and temporal patterns of severe pneumonia causing critical illness during Hajj. BMC Infect Dis. 2012;12(1):1-8. doi:10.1186/ 1471-2334-12-117

12. Madani TA, Ghabrah TM, Al-Hedaithy MA, et al. Causes of hospitalization of pilgrims during the hajj period of the islamic year 1423 (2003). Ann Saudi Med. 2006;26(5):346-351. doi:10.5144/02564947.2006.346

13. Hajj Statistics. 2018/1439: general authority for statistics. Available from: https://www.stats.gov.sa/en/6060. Accessed January 5, 2020.

14. Rahman J, Thu M, Arshad N, Van der Putten M. Mass gatherings and public health: case studies from the Hajj to Mecca. Ann Glob Health. 2017;83(2):386-393. doi:10.1016/j.aogh.2016.12.001

15. Sridhar S, Benkouiten S, Belhouchat K, et al. Foot ailments during hajj: a short report. JEGH. 2015;5(3):291-294. doi:10.1016/j. jegh.2014.12.007

16. Hajj: what to Expect. Available from: https://hajjumrahplanner.com/ hajj-what-to-expect/. Accessed January 11, 2020.

17. Mimesh SA, Al-Khenaizan S, Memish ZA. Dermatologic challenges of pilgrimage. Clin Dermatol. 2008;26(1):52-61. doi:10.1016/j. clindermatol.2007.09.019

18. Clingingsmith D, Khwaja AI, Kremer M. Estimating the impact of the hajj: religion and tolerance in islam's global gathering. $Q J$ Econ. 2009;124(3):1133-1170. doi:10.1162/qjec.2009.124.3.1133

19. Koubâa A, Ammar A, Benjdira B, et al. Activity monitoring of islamic prayer (salat) postures using deep learning. IEEE. 2020;106-111.

20. Al-Asmary S, Al-Shehri A-S, Abou-Zeid A, Abdel-Fattah M, Hifnawy T, El-Said T. Acute respiratory tract infections among hajj medical mission personnel, Saudi Arabia. Int J Infect Dis. 2007;11 (3):268-272. doi:10.1016/j.jijid.2006.04.008

21. Alzeer AH. Respiratory tract infection during hajj. Ann Thorac Med. 2009;4(2):50-53. doi:10.4103/1817-1737.49412

22. Al Shimemeri A. Cardiovascular disease in hajj pilgrims. J Saudi Heart Assoc. 2012;24(2):123-127. doi:10.1016/j.jsha.2012.02.004 
23. Gautret P, Soula G, Delmont J, Parola P, Brouqui P. Common health hazards in French pilgrims during the hajj of 2007: a prospective cohort study. J Travel Med. 2009;16(6):377-381. doi:10.1111/j.17088305.2009.00358.x

24. Fatani MI, Al-Afif KA, Hussain H. Pattern of skin diseases among pilgrims during hajj season in Makkah, Saudi Arabia. Int J Dermatol. 2000;39(7):493-496. doi:10.1046/j.1365-4362.2000.00009.x

25. Alfelali M, Barasheed O, Alshehri J, et al. Foot injuries among hajj pilgrims with and without diabetes mellitus: implications for infection management. Infect Disord Drug Targets. 2014;14(2):140-147. doi:10.2174/1871526514666140713160413

26. Hajj Statistics 2017/1438: general authority for statistics. Available from: https:/www.stats.gov.sa/en/5633. Accessed January 5, 2020.

27. Ahacic K, Kåreholt I. Prevalence of musculoskeletal pain in the general Swedish population from 1968 to 2002: age, period, and cohort patterns. Pain. 2010;151(1):206-214. doi:10.1016/j.pain.2010.07.011

28. Holzer BM, Siebenhuener K, Bopp M, Minder CE. Evidence-based design recommendations for prevalence studies on multimorbidity: improving comparability of estimates. Popul Health Metr. 2017;15 (1):1-9. doi:10.1186/s12963-017-0126-4

29. Wijnhoven HA, De Vet HC, Picavet HSJ. Prevalence of musculoskeletal disorders is systematically higher in women than in men. Clin J Pain. 2006;22(8):717-724. doi:10.1097/01.ajp.0000210912.95664.53

30. Savu A, Liu Q, Yasui Y. Estimation of relative risk and prevalence ratio. Stat Med. 2010;29(22):2269-2281. doi:10.1002/sim.3989

31. Cipriani A, Nosè M, Barbui C. What is a risk ratio? Epidemiol Psychiatr Sci. 2007;16(1):20-21. doi:10.1017/S1121189X00004577

32. Akinpelu AO, Oyewole OO, Odole AC, Olukoya R. Prevalence of musculoskeletal pain and health seeking behaviour among occupational drivers in Ibadan, Nigeria. Afr J Biomed Res. 2011;14(2):89-94.

33. Eriksen W. The prevalence of musculoskeletal pain in Norwegian nurses' aides. Int Arch Occup Environ Health. 2003;76(8):625-630. doi:10.1007/s00420-003-0453-6

34. Sharan D, Rajkumar JS, Balakrishnan R. 644 risk factors for work related musculoskeletal disorders among physiotherapists. Occup Environ Med. 2018;75(Suppl 2):A183-A184.

35. Mahto PK, Gautam BB. Prevalence of work-related musculoskeletal disorders in agricultural farmers of Bhaktapur District, Nepal. IJOSH. 2018;8(1):3-7.

36. Pargali N, Jowkar N. Prevalence of musculoskeletal pain among dentists in Shiraz, Southern Iran. Int J Occup Environ Med. 2010;1 (2):69-74.

37. Teixeira RN, Lunardi A, da Silva RA, Lopes AD, Carvalho CR. Prevalence of musculoskeletal pain in marathon runners who compete at the elite level. Int J Sports Phys Ther. 2016;11(1):126-131.

38. Ellapen T, Satyendra S, Morris J, Van Heerden H. Common running musculoskeletal injuries among recreational half-marathon runners in KwaZulu-Natal. $S$ Afr $J$ Sports Med. 2013;25(2):39-43. doi:10.17159/2078-516X/2013/v25i2a372

39. Bergman S, Herrström P, Högström K, Petersson IF, Svensson B, Jacobsson LT. Chronic musculoskeletal pain, prevalence rates, and sociodemographic associations in a Swedish population study. $J$ Rheumatol. 2001;28(6):1369-1377.

40. Bezerra MAM, Hellwig N, Pinheiro G, Lopes CS. Prevalence of chronic musculoskeletal conditions and associated factors in Brazilian adults - national health survey. BMC Public Health. 2018;18(1):1-10

41. Nakamura M, Nishiwaki Y, Ushida T, Toyama Y. Prevalence and characteristics of chronic musculoskeletal pain in Japan. J Orthop Sci. 2011;16(4):424-432. doi:10.1007/s00776-011-0102-y

42. Lami F, Hameed I, Jewad AW, Khader Y, Amiri M. Real-time surveillance of infectious diseases and other health conditions during Iraq's Arbaeenia mass gathering: cross-Sectional Study. JMIR Public Health Surveill. 2019;5(4):e14510. doi:10.2196/14510
43. Marashi SA, Rusta H, Tabatabaei A. Chief complaints and diagnosis of patients visited by caravan physicians during hajj 2010. Iran Red Crescent Med J. 2014;16(12):e12858. doi:10.5812/ircmj.12858

44. Reed LF, Battistutta D, Young J, Newman B. Prevalence and risk factors for foot and ankle musculoskeletal disorders experienced by nurses. BMC Musculoskelet Disord. 2014;15(1):196. doi:10.1186/ 1471-2474-15-196

45. Munazila A, Shahana S, Rajan M, Sandeep K, Baba MR. Prevalence of foot and ankle pain among housekeeping staffs-a Cross Sectional Study. Indian J Physiother Occup Ther. 2020;13(1):37-42.

46. Widanarko B, Legg S, Stevenson M, et al. Prevalence of musculoskeletal symptoms in relation to gender, age, and occupational/industrial group. Int $J$ Ind Ergon. 2011;41(5):561-572. doi:10.1016/j. ergon.2011.06.002

47. Picavet H, Schouten J. Musculoskeletal pain in the Netherlands: prevalences, consequences and risk groups, the DMC3-study. Pain. 2003;102(1-2):167-178. doi:10.1016/s0304-3959(02)00372-X

48. Hsu C-L, Yang C-H, Wang J-H, Liang -C-C. Common running musculoskeletal injuries and associated factors among recreational gorge marathon runners: an investigation from 2013 to 2018 taroko gorge marathons. Int J Environ Res Public Health. 2020;17(21):8101. doi:10.3390/ijerph17218101

49. Hill CL, Gill TK, Menz HB, Taylor AW. Prevalence and correlates of foot pain in a population-based study: the North West Adelaide health study. J Foot Ankle Res. 2008;1(1):2. doi:10.1186/1757-1146-1-2

50. Thomas MJ, Roddy E, Zhang W, Menz HB, Hannan MT, Peat GM. The population prevalence of foot and ankle pain in middle and old age: a systematic review. Pain. 2011;152(12):2870-2880. doi:10.1016/j.pain.2011.09.019

51. Abdulmonem A, Hanan A, Elaf A, Haneen T, Jenan A. The prevalence of musculoskeletal pain \& its associated factors among female Saudi school teachers. Pak J Med Sci. 2014;30(6):1191-1196. doi:10.12669/pjms.306.5778

52. Leroux I, Dionne CE, Bourbonnais R, Brisson C. Prevalence of musculoskeletal pain and associated factors in the quebec working population. Int Arch Occup Environ Health. 2005;78(5):379-386. doi:10.1007/s00420-004-0578-2

53. Buldt AK, Menz HB. Incorrectly fitted footwear, foot pain and foot disorders: a systematic search and narrative review of the literature. $J$ Foot Ankle Res. 2018;11(1):43. doi:10.1186/s13047-018-0284-z

54. de Castro AP, Rebelatto JR, Aurichio TR. The relationship between wearing incorrectly sized shoes and foot dimensions, foot pain, and diabetes. J Sport Rehabil. 2010;19(2):214-225. doi:10.1123/ jsr.19.2.214

55. Leveille SG, Jones RN, Kiely DK, et al. Chronic musculoskeletal pain and the occurrence of falls in an older population. JAMA. 2009;302(20):2214-2221.

56. Umer W, Antwi-Afari MF, Li H, Szeto GP, Wong AY. The prevalence of musculoskeletal symptoms in the construction industry: a systematic review and meta-analysis. Int Arch Occup Environ Health. 2018;91(2):125-144.

57. Gran JT. The epidemiology of chronic generalized musculoskeletal pain. Best Pract Res Clin Rheumatol. 2003;17(4):547-561. doi:10.1016/S1521-6942(03)00042-1

58. Mølgaard C, Lundbye-Christensen S, Simonsen O. High prevalence of foot problems in the Danish population: a survey of causes and associations. Foot. 2010;20(1):7-11. doi:10.1016/j.foot.2010.03.002

59. Tojo M, Yamaguchi S, Amano N, et al. Prevalence and associated factors of foot and ankle pain among nurses at a university hospital in Japan: a cross-sectional study. J Occup Health. 2018;60(2):132-139. doi:10.1539/joh.17-0174-OA 


\section{Publish your work in this journal}

The Journal of Pain Research is an international, peer reviewed, open access, online journal that welcomes laboratory and clinical findings in the fields of pain research and the prevention and management of pain. Original research, reviews, symposium reports, hypothesis formation and commentaries are all considered for publication. The manuscript management system is completely online and includes a very quick and fair peer-review system, which is all easy to use. Visit http:// www.dovepress.com/testimonials.php to read real quotes from published authors. 